\title{
Public health law, human rights and HIV: a work in progress
}

\author{
Stevie Clayton \\ Former Chief Executive Officer of the AIDS Council of NSW \\ Email: stevie@thinkchange.net.au
}

\begin{abstract}
Australia has been a global leader in balancing public health law, human rights and HIV. The first National HIV/AIDS Strategy launched in 1989 set the agenda for law reform. The Intergovernmental Committee on AIDS subsequently established a legal working party with one of its key tasks to formulate public health legislation that would protect public health and human rights. The NSW Public Health Act 1991 has provided the framework for managing HIV in NSW over the subsequent decades. Recent changes to criminal law in NSW and opportunities to redefine public health law may affect how HIV transmission risks are managed in the future.
\end{abstract}

From early in the human immunodeficiency virus (HIV) epidemic, governments in Australia recognised that an effective response to HIV required strategies that went beyond the traditional public health remedies of abatement, control, notification or isolation. This is in part due to the leadership provided by the then Federal Minister for Health, and then Community Services and Health, Dr Neal Blewett, in shaping an effective public health response over the period 1983 to 1990.

Key elements in the Australian response were the partnerships established with affected communities and the recognition given to the rights of marginalised people at risk of HIV, including the need to strengthen these rights, to enable community members to make healthier life choices. Of particular importance was the early recognition that public health objectives would be most effectively realised if human rights are respected, a principle that holds public health and human rights issues as complementary rather than oppositional. Respect for human rights protects those who are vulnerable and marginalised, establishes trust for efforts to access populations that are hard-to-reach, promotes confidence in health services, and secures the cooperation necessary for preventing further transmission. This article describes the role of law reform in supporting HIV prevention and care in Australia since the beginning of the 1980s.

Law reform was recognised as essential to the strengthening of rights and was taken up as a key element in the agenda of the First National HIV/AIDS Strategy released in November 1989. ${ }^{1}$ The Government's commitment to law reform to protect public health was articulated by then Deputy Prime Minister, Mr Brian Howe: 'This Government recognises the high priority of AIDS law reform in eliminating transmission of HIV through the removal of legal impediments to prevention efforts ... and [to] minimise the personal and social impacts of HIV'. ${ }^{2}$

\section{National legislative response to HIV}

The law reform agenda was subsequently progressed through a Legal Working Party established under the Intergovernmental Committee on AIDS. A key task of the Legal Working Party was to formulate '... public health legislation which would balance individual human rights with the need to protect the wider community'. ${ }^{2}$ A reform program was developed which included HIVspecific laws such as: notification of cases; confidentiality of information; and sanctions for transmission but also reforms to help create an enabling environment for HIV prevention.

\section{NSW legislative response to HIV}

In New South Wales (NSW), the Public Health Act 1991 includes provisions based on the same principles as adopted on a national basis by the Legal Working Party and provides the legislative framework for the notification of HIV, the key protections for and obligations of people with HIV and powers for public health management. The legislation had an important enabling function in the state's response to HIV. For example, sections $14-16$ require the notification of all new HIV diagnoses to the NSW Department of Health. The resulting surveillance information identifies transmission risks and enables health promotion interventions to be directed to populations with the greatest need. 


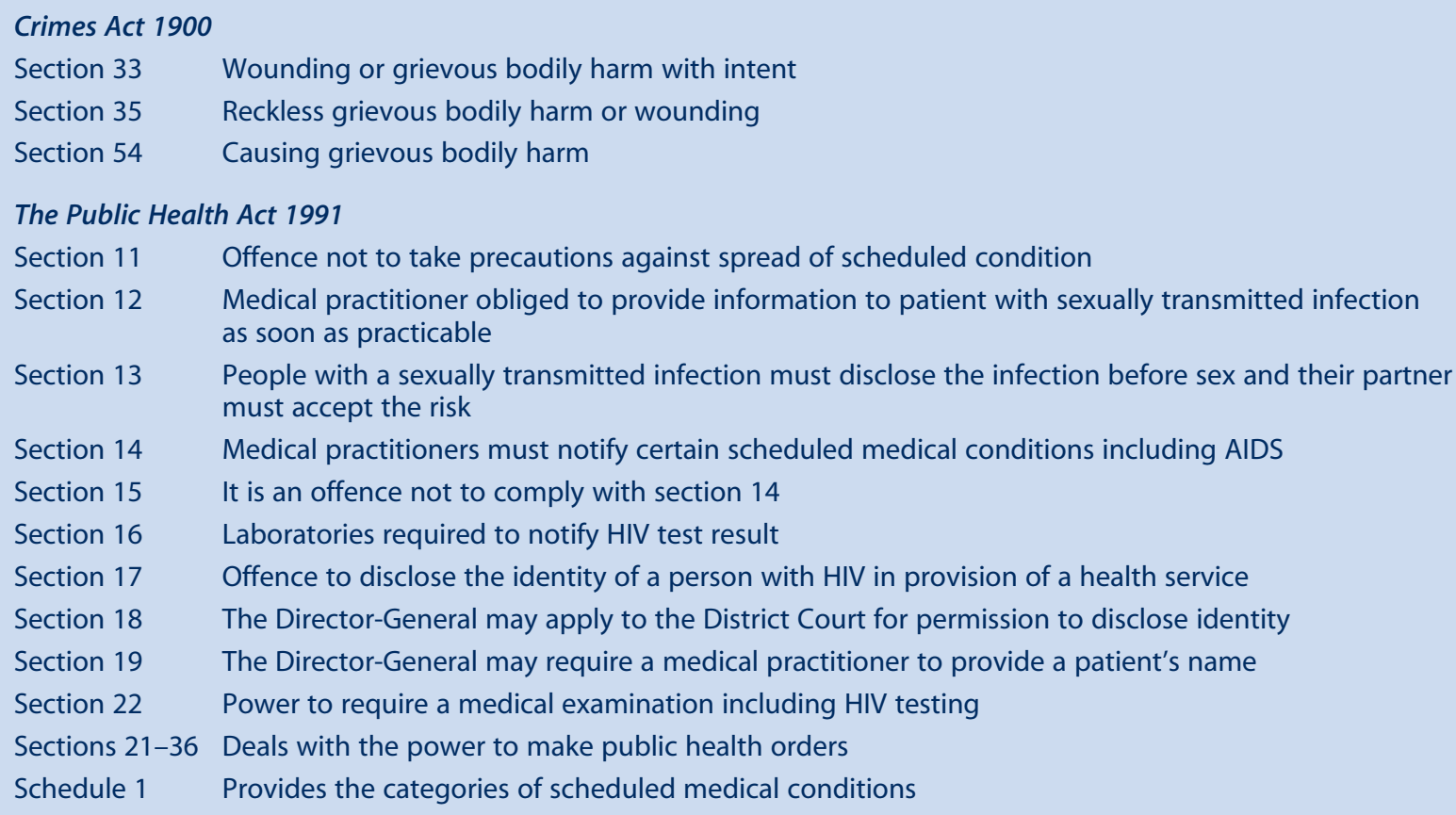

Section 17 of the Act protects the identity of people with HIV by prohibiting the inclusion of the name or address of a patient on these notifications and by making it an offence for a person providing a service to disclose HIV status without consent, except to others also providing care, treatment or counselling, or where required by law. With the concerns about stigma and discrimination associated with HIV, protection of personal information has supported access to testing for HIV by risk populations. Testing and diagnosis of HIV are essential with approximately onethird of HIV infections among gay men estimated to involve a person with undiagnosed HIV infection. ${ }^{3}$

The Public Health Act 1991 is supported by other legislation including the Health Records and Information Privacy Act 2002, and by NSW Department of Health Policy Directives including PD2005_593: NSW Health Privacy Manual $^{4}$ and PD2009_023: Management of people with $H I V$ who risk infecting others. ${ }^{5}$ This latter policy provides a framework for the management of people with HIV whose behaviours represent a risk to public health and establishes an expert Assessment Panel to provide advice to treating clinicians and the NSW Chief Health Officer in circumstances of HIV-related public health risk. Box 1 provides a list of the relevant sections in the Crimes Act 1900 and the Public Health Act 1991 that are relevant to the management of HIV.

While the NSW Policy Directive for managing cases of HIV-related public health risk is consistent with the national framework (agreed by all jurisdictions in 2009), ${ }^{6}$ the Public Health Act 1991 differs from all other jurisdictions except Tasmania in that section 13 requires people with a sexually transmissible medical condition (including HIV) to disclose their infection to potential sexual partners before intercourse and for the sexual partner to voluntarily accept the risk. There is no provision for a defence of safe sex.

\section{Application of the legislation}

Even though section 13 has been infrequently used (only one person was charged and convicted in NSW during the period 2000 and 2008), ${ }^{7}$ it can be argued that the requirement to disclose builds community expectations that people with HIV are aware of their infection and will disclose that information to others. Potentially the requirement also discourages testing, places the emphasis on disclosure rather than on safe sex, and shifts the responsibility for prevention disproportionately onto people with HIV. ${ }^{8}$

A small number of people with HIV face difficulty making informed choices due to mental illness, intellectual disability, drug dependence, socioeconomic conditions or other factors. People in this group are more likely to be identified and labelled as 'people with HIV who risk infecting others' and their behaviours managed through public health officers in area health services, the expert Assessment Panel that advises the Chief Health Officer, and by Public Health Orders made under the Act. Even so, public health is about protecting and enhancing every human's rights, as individuals and as members of their community. In cases where the rights of the individual are in conflict with the rights of others decisions must be made 
on the basis of the least harsh option. ${ }^{9}$ Despite these safeguards, constant vigilance is required to ensure socially vulnerable people are not disadvantaged.

In NSW, people with HIV who risk passing the infection to others due to difficulties in making informed choices are generally not managed through the extremities of the Act or the Policy Directive. Considerable resources from both public agencies and community-based organisations are directed as required for the prevention of HIV public health risks in these circumstances. In particular, case management including behaviour management delivered through specialised HIV services and with advice from the Assessment Panel, generally enables those with HIV risks to enter a stable, ongoing medical-care system with supported prevention goals. ${ }^{10}$

This approach to management has provided a balance of individual human rights, needs for health and other support, and the need to protect the wider community.

\section{Emerging issues}

From 1997, the federal and state governments, through the National Public Health Partnership, committed significant resources to redefining public health law. ${ }^{9}$ It resulted in new legislation in Victoria, Tasmania and the Australian Capital Territory. ${ }^{11}$ Draft bills are under consideration in South Australia and Western Australia. ${ }^{12}$ In February 2010, the NSW Government released for consultation the NSW Public Health Bill 2010.

The words 'human rights' are not used in contemporary public health legislation. A new underlying theme in public health law is, instead, the identification and management of risk with a clear statement about evidence-informed decision making; the primacy of prevention; proportionality and equity (see in particular: ss5-10 Public Health and Wellbeing Act 2008 [Vic.] and ss5-13 Public Health Bill 2009 [SA]). This is further reinforced by a set of principles. This shift has occurred in parallel with a growth in the health and human rights movement. ${ }^{13}$ As a 'human rights approach requires a fair balance to be achieved between the interests of people who are, may be, or are not infected with diseases such as HIV/AIDS', ${ }^{14}$ the requirements of risk management and proportionality of the newer legislation may ultimately be in conflict with the objectives of the health and human rights movement.

In addition, there has been an apparent increase in Australia in the number of people with HIV charged with HIVtransmission offences. Although the number of court cases occurring in NSW remains relatively low (the National Association of People Living with HIV/AIDS cites the 2004 Kanengele-Yondjo case ${ }^{15}$ and the 2008 Montgomery case as being of note), ${ }^{16}$ this trend may change.
Until recently the NSW Crimes Act 1900 included specific provisions for dealing with a person who 'maliciously caused another person to contract a grievous bodily disease' ${ }^{17}$ When tested in practice, the provision was found to be unworkable because "the requirement to prove the actions were carried out "maliciously" was too onerous to prove, particularly when the accused had had sex on other occasions with women who did not contract the virus'. ${ }^{15}$ The response of the NSW government was to amend the definition of grievous bodily harm in section 4 of the Act to include infliction of a grievous bodily disease, making the general grievous bodily harm sections 33,35 and 54 the relevant offences.

With these changes, the criminal law in NSW is now consistent with the UNAIDS International Guidelines on HIV/AIDS and Human Rights which state that no country should have criminal laws targeting people with HIV as general laws should be adequate. ${ }^{18}$ There is however increased opportunity afforded in the legislation to criminalise HIV transmission. Should increased criminalisation occur, individuals ultimately are stigmatised and blamed: a shift away from shared responsibilities - a key health promotion message of HIV interventions to date.

\section{Unfinished business}

With the groups most affected by HIV - gay men, people who inject drugs and sex workers - being marginalised in society, any consideration of public health law and human rights must also include policy, legislation and social vulnerabilities that impact on access to health services and the adoption of healthy behaviours. For this reason the final Legal Working Party Report recommended changes such as recognition of same-sex relationships, national decriminalisation of the sex industry, and repeal of drug self-administration offences.

While some progress was made, including the 1995 decriminalisation of the NSW sex industry, not all recommendations of the Legal Working Party have been implemented. Further, with a changing epidemic, issues have arisen that were not previously contemplated. Stigma and discrimination remain ever present for people with HIV; gay men do not yet have equality; the sex industry needs consistent national regulation and changes are needed to better allow the distribution of new injecting drug equipment.

\section{Conclusion}

In 2010, there are no longer structures to coordinate HIV legal policy or legislative reform at a state or national level. The sense of crisis that drove initial efforts to ensure the law served public health was lost as, with improvements in combination antiretroviral therapy during the 1990s, HIV increasingly became considered a chronic, manageable 
condition. However, changes in the state of the epidemic have seen a movement away from a rights-based approach towards a medical management model. ${ }^{19}$ The health and human rights movement may need to re-invigorate the debate on rights and HIV.

\section{References}

1. Department of Community Services and Health. National HIV/ AIDS Strategy: a policy information paper. Canberra: Australian Government Publishing Service; 1989.

2. IGCA Legal Working Party. Final Report of the Legal Working Party of the Intergovernmental Committee on AIDS. Canberra: Department of Health, Housing and Community Services; 1992.

3. Wilson DP, Hoare A, Regan DG, Law MG. Importance of promoting HIV testing for preventing secondary transmissions: modelling the Australian HIV epidemic among men who have sex with men. Sex Health 2009; 6: 19-33. Available from: http:// www.publish.csiro.au/?act=view_file\&file_id=SH08081.pdf (Cited 19 March 2010.) doi:10.1071/SH08081

4. NSW Health. Policy Directive. Privacy Manual (Version 2). PD2005_593. 3 June 2005. Available from: http://www.health. nsw.gov.au/policies/pd/2005/PD2005_593.html (Cited 19 March 2010.)

5. NSW Health. Policy Directive. HIV - Management of people with HIV infection who risk infecting others. PD2009_023. 28 April 2009. Available from: http://www.health.nsw.gov.au/ policies/pd/2009/PD2009_023.html (Cited 19 March 2010.)

6. National guidelines for the management of people with HIV who place others at risk. Endorsed by Health Ministers' Conference. 18 April 2008. Available from: http://www.nhhrc.org.au/internet/ main/publishing.nsf/Content/BF51F1922544BA6FCA2574 DA007FE597/\$File/hiv-at-risk.pdf (Cited 19 March 2010.)

7. Statistics supplied by the NSW Bureau of Crime Statistics and Research. 2 March 2010.

8. Lake R. Don't ask, don't tell? Disclosure and HIV. HIV in Australia. HIV Australia: Legal section 2009; 6(4). Available from: http://www.afao.com.au/view_articles.asp?pxa= ve \&pxs $=103 \&$ pxsc $=127 \&$ pxsgc $=139 \& \mathrm{id}=701$ (Cited 19 March 2010.)

9. Reynolds CS. Public health law in the new century. J Law Med 2003; 10(4): 435-41.

10. US Center for Disease Control and Prevention. HIV Prevention through case management for HIV-infected persons - selected sites, United States, 1989-1992. CDC MMWR Wkly 1993; 42(23): 448-9. Available from: http://www.cdc.gov/mmwr/pre view/mmwrhtml/00020823.htm (Cited 18 March 2010.)

11. Public Health and Wellbeing Act 2008 (Vic); Public Health Act 1997 (Tas); and Public Health Act 1997 (ACT).

12. Public Health Bill 2009 (SA) and A New Public Health Act for WA 2009.

13. Hunt P. The health and human rights movement: Progress and obstacles. J Law Med 2008; 15(5): 714-24.

14. Watchirs H. Public health, criminal law and HIV/AIDS. In: HIV and hepatitis $\mathrm{C}$ - policy, discrimination, legal issues. Sydney: Australian Society for HIV Medicine; 2005. p. 72.

15. Kanengele-Yondjo v Regina [2006] NSWCCA 354.

16. National Association of People Living with HIV/AIDS (NAPWA). The criminalisation of HIV transmission in Australia: legality, morality and reality. Sydney: NAPWA monograph; 2009.

17. Former section 36 Crimes Act 1900 (NSW).

18. Office of the United Nations High Commissioner for Human Rights and the Joint United Nations Programme on HIV/AIDS. International Guidelines on HIV/AIDS and Human Rights 2006 Consolidated Version. Geneva; 2006. Available from: http://data.unaids.org/Publications/IRC-pub07/jc1252internguidelines_en.pdf (Cited 19 March 2010.)

19. Godwin J. Unfinished business: reflections on Australia's efforts to embed human rights in our HIV responses. HIV in Australia 2009; 7(1). Available from: http://www.afao.com.au/view_ articles.asp?pxa $=$ ve \&pxs $=103 \&$ pxsc $=127 \&$ pxsgc $=139 \& \mathrm{id}=$ 719 (Cited 19 March 2010.) 